\title{
THE RELATIVE AGE EFFECT IN BRAZILIAN ELITE SOCCER DEPENDING ON AGE CATEGORY, PLAYING POSITION, AND COMPETITIVE LEVEL
}

original paper

() Wroclaw University of Health and Sport Sciences

DOI: https://doi.org/10.5114/hm.2022.109070

\author{
LUCAS S. FIGUEIREDO ${ }^{1,2}$, LUCAS M.S. GOMES ${ }^{3}$, DRUMOND G. DA SILVA ${ }^{3,4}$, \\ PETRUS GANTOIS ${ }^{5}$, JOÃO V.A.P. FIALHO ${ }^{6}$, LEONARDO S. FORTES $^{5}$, FABIANO S. FONSECA ${ }^{3}$ \\ ${ }^{1}$ Federal University of Minas Gerais, Belo Horizonte, Brazil \\ ${ }^{2}$ Aeronautical Instruction and Adaptation Centre, Lagoa Santa, Brazil \\ ${ }^{3}$ Federal Rural University of Pernambuco, Recife, Brazil \\ ${ }^{4}$ Federal University of Pernambuco, Recife, Brazil \\ ${ }^{5}$ Federal University of Paraíba, João Pessoa, Brazil \\ ${ }^{6}$ América Soccer Club, Belo Horizonte, Brazil
}

\begin{abstract} age categories, playing position, and competitive level. level (Series A or B).

\section{Introduction}

In youth sports organizations around the world, children and adolescents are categorized in accordance with annual age grouping policies. The main purpose of this process is to provide young athletes with fair competition and equal opportunities to develop their skills [1]. However, differences in chronological age within the same age cohort are expected owing to the inherent variability in biological developmental processes [2]. Children born closer to the cut-off
\end{abstract}

Purpose. This study investigated the occurrence of relative age effect (RAE) in Brazilian elite soccer athletes depending on

Methods. Data from 2660 male elite soccer athletes who participated in the 2019 Brazilian soccer championships were analysed. To determine RAE, the players were divided by their quarter of birth: Q1 (January-March), Q2 (April-June), Q3 (July-September), and Q4 (October-December). Data were obtained from the Brazilian Soccer Confederation (CBF) official website, and from each club's website when no information was available at the CBF website. Were included the athletes who participated in the 2019 Brazilian soccer championships in series A and B. Data were organized in accordance with age categories (under-20 or senior), playing position (forwards, midfielders, defenders, and goalkeepers), and competitive

Results. An overrepresentation of soccer players born in the first quarter of the year was found when compared with the other quarters, whereas players born in the last quarter of the year were underrepresented, regardless of the age category and competitive level. Regarding playing position, an overrepresentation of soccer players born in the first quarter of the year was found for all playing positions in both age categories, except for the goalkeepers in the senior category.

Conclusions. Our results showed a prevalence of RAE in U-20 and senior age categories in elite Brazilian soccer athletes, in both competitive levels, and for all playing positions, except for goalkeepers in the senior category.

Key words: relative age effect, elite soccer athletes, selection process bias, maturation

date are more likely to be more developed in cognitive, psychological, and physical aspects than players born further from the cut-off date [2, 3]. The consequences generated by the chronological differences among athletes in the same age group are known as the relative age effect (RAE). In this regard, RAE provides an immediate competitive advantage, within the same age group, to relatively older players and disadvantages for relatively younger athletes, which can be reflected in higher dropout rates and lower chances to achieve long-term success in sport $[4,5]$.

Correspondence address: Lucas Savassi Figueiredo, Universidade Federal de Minas Gerais, Av. Presidente Carlos Luz, 6627, Belo Horizonte, Minas Gerais, 31270-901, Brazil, e-mail: savassi88@hotmail.com

Received: April 24, 2021

Accepted for publication: May 5, 2021

Citation: Figueiredo LS, Gomes LMS, da Silva DG, Gantois P, Fialho JVAP, Fortes LS, Fonseca FS. The relative age effect in Brazilian elite soccer depending on age category, playing position, and competitive level. Hum Mov. 2022;23(2):112-120; doi: https://doi.org/10.5114/hm.2022.109070. 
RAE is a widespread phenomenon across many sports, especially team sports $[3,6,7]$. This effect manifests to a greater extent in young male athletes, especially in highly competitive contexts $[1,3,8]$. Thus, as it could be expected, RAE is well established in the Brazilian youth soccer [9-11], where a large pool of athletes competes for a limited number of spots. Since soccer is a sport characterized by high physical and physiological demands [12, 13], coaches are biased towards selecting those athletes who present better developed physical attributes. One aspect to consider is that inter-individual variations related to growth and maturity are especially pronounced in infancy and adolescence [2], that is, when talent selection processes usually occur. Consequently, relatively older athletes are more likely to progress in sport than relatively younger players because of a 'biased' view of their real potential [3].

The primary mechanism that explains the occurrence of RAE as a bias factor in the early stages of the athletes' development process is the role of physical maturation (i.e. maturation-selection hypothesis) [3]. Although the RAE phenomenon exists, its consequences tend to disappear when the age category and competition level increase, and the athletes have already gone through the growth spurt (e.g. under-20 and senior). Nevertheless, sometimes RAE is so pervasive in youth categories that it remains up to U-20 and even senior categories $[5,7,14,15]$. This phenomenon may cause the systematic loss of potential sporting talents as a result of biased decisions made in the earlier age categories.

RAE is a multifactorial phenomenon in nature, and many aspects associated with the individual, the environment, and the task constraints provide a theoretical rationale to explain its occurrence in different sports contexts [8]. Among several aspects, the relationship between playing position and RAE has received attention in recent years. In soccer, some studies were carried out to verify whether the specific demands of each playing position could modulate the occurrence of RAE. Romann and Fuchslocher [16] addressed this matter in elite Swiss junior soccer players and found that relatively older defenders were overrepresented compared with the other playing positions, suggesting that RAE might be determined by playing position. Conversely, Campos et al. [14] investigated elite U-20 South American soccer athletes and observed RAE in all playing positions, except for goalkeepers. Thereby, to date, the effect of playing position on RAE in soccer is still controversial and seems context-dependent. Hence, the relationship between RAE and playing positions remains a topic to be addressed in the Brazilian soccer system.

Another factor that may modulate RAE is the competitive level. Overall, the most skilled players are expected to play in more competitive tiers (Series A in the case of Brazilian soccer). The lower divisions (Series $\mathrm{B}$ ), on the other hand, could serve as back doors for the first-tiers competitions, being especially important for players who might have previously been neglected owing to maturational aspects [5]. Aiming to verify whether the second tiers leagues indeed represented a second opportunity for late-born athletes, Rađa et al. [5] investigated RAE in first and second tiers leagues in 5 of the most prestigious European soccer leagues. The results indicated that RAE occurred in the same magnitude in both tiers, which may reduce the chance for late-born athletes to reach first tiers leagues.

Despite the fact that RAE is a widely investigated phenomenon in soccer, most research on this topic referred to European leagues [17, 18]. The European context has different characteristics from Brazil with regard to organizational structure, competitive level, selection, training, and development of talents for soccer. To illustrate, recent evidence indicates that Brazilian players born in the first 6 months of the year, from cities with a demographic rate of up to 100,000 inhabitants and a Human Development Index above 0.501, are more likely to reach the elite of Brazilian soccer (Series A) [19]. Considering that the occurrence and magnitude of RAE seems to be directly influenced by environmental constraints [8], it is relevant to explore how this phenomenon manifests itself in the Brazilian soccer context. This is particularly necessary because studies that investigated RAE among Brazilian elite soccer athletes are limited. Costa et al. [20] studied RAE depending on the competitive level (Series A and B) in the 2008 elite Brazilian championship and confirmed the presence of this effect in both tiers of competition. More recently, a historical analysis that comprised a wide sample of players born in years 1921-1996 showed that RAE was present in the Brazilian soccer system during the decades of 1960s, 1970s, 1980s, and 1990s [21]. However, current data on RAE existence among elite athletes in the Brazilian soccer are scarce in the literature. Additionally, to the limit of our knowledge, previous studies did not account for the players' competitive levels, playing positions, and age categories together, precluding specific conclusions regarding the roles of these aspects on RAE occurrence in the Brazilian soccer system. A broad analysis of RAE among Brazilian elite players has im- 
portant practical implications for different reasons. Soccer is a sport played by millions of children and teenagers in the country. The institutional policies used by federations and methodological approaches applied by professionals during the selection of young athletes can influence the formation and development of talents for the sport. Sports systems in which RAE is predominant may result in the loss of potential talents because of inequalities generated by age grouping systems based on athletes' birthdates [1, 3, 22]. Therefore, investigating how RAE manifests depending on age category, playing position, and competitive level is crucial to reduce potential inequalities in the Brazilian soccer system.

This study aimed to investigate the existence of RAE in Brazilian elite soccer athletes from U-20 and senior categories. Moreover, we sought to observe whether playing position and competitive level were associated with RAE. We hypothesized that RAE would be found in athletes from both age categories, with a smaller effect in the senior category, with small expected maturation differences [2]. Moreover, we expected to verify RAE regardless of playing positions or competitive level, owing to the highly competitive nature of the Brazilian soccer system, which increases the likelihood of RAE [1].

\section{Material and methods}

\section{Participants}

The sample of this study was composed of 2660 male elite soccer athletes who were part of the U-20 (mean age: $18.6 \pm 1.1$ years) and senior (mean age: 26.0 \pm 4.9 years) squads of professional teams that participated in the 2019 Brazilian soccer championships, in series A or B (first and second tiers of the Brazilian soccer championships, respectively). The athletes were organized by the variable analysed as follows: age category (U-20, $n=1471$; senior, $n=1189$ ); competitive level (series A, $n=1399$; series B, $n=1261$ ); playing position (forwards, $n=647$; midfielders, $n=902$; defenders, $n=837$; goalkeepers, $n=274$ ).

\section{Data collection and procedures}

Data were obtained from rosters available at the Brazilian Soccer Confederation (CBF) official website (www.cbf.com.br). When no information was available at the CBF website, the clubs' websites were consulted. Data collection was performed in January 2019. The information obtained included players' full names, dates of birth, playing positions, and age categories. Athletes whose information was incomplete were not considered for the study.

The cut-off date for youth categories of teams participating in the Brazilian soccer championships is January 1 (quarters are composed as a function of this cut-off). The variables analysed included the quarters of the year the athletes were born: Q1 (January, February, March), Q2 (April, May, June), Q3 (July, August, September), and Q4 (October, November, December), and were split depending on age categories (U-20 and senior), competitive levels (Series A and B), and playing positions (forwards, midfielders, defenders, and goalkeepers). Players who composed a squad in more than one category were considered only once in the analysis, on the playing position they played in the senior category.

\section{Statistical analysis}

Athletes' frequencies were presented in absolute and relative values. We analysed the occurrence of RAE among players by comparing the frequency of athletes born in each quarter observed in our sample and the frequency expected (Exp) for the Brazilian population on the basis of Brazilian reports. This is a methodological procedure traditionally used in the RAE literature with the purpose of minimizing the bias associated with seasonal variations in the birth rate between months of the year [22, 23]. Thus, in our analysis, we considered the number of births in each quarter of the year based on Brazilian reports from 1994-2001 (Brazilian Ministry of Health), which led to the following expected observations for each quarter: Q1: $25.7 \%$, Q2: $26.3 \%$, Q3: $24.8 \%$, and Q4: $=23.2 \%$.

A chi-square test $\left(\chi^{2}\right)$ was performed to compare the athletes' birthdates distribution depending on sex, event type, and age category. For all analyses, the effect size $(\omega)$ of the chi-square tests was calculated. Additionally, odds ratio $(O R)$ and $95 \%$ confidence interval for Q1 vs. Q4 and first semester vs. second semester were calculated. Analyses were performed in the Statistical Package for the Social Sciences (SPSS), version 20.0 (Chicago, USA). The level of significance was 0.05 . Whenever multiple comparisons between quarters were necessary, Bonferroni's corrections were performed. In these cases, the significance level was adjusted to 0.008 .

\section{Ethical approval}

The conducted research is not related to either human or animal use. 


\section{Results}

Birthdate distribution by quarters

Figure 1 shows the relative frequency of the observed and expected birthdate distribution of the pooled Brazilian soccer players. Our analysis indicated an uneven distribution of birthdates $(p<0.001 ; \omega=0.33$; $\mathrm{Q} 1=970 ; \operatorname{Exp}=682.6 ; \mathrm{Q} 2=830 ; \operatorname{Exp}=701.4 ; \mathrm{Q} 3=$ 502; $\operatorname{Exp} 660.5 ; \mathrm{Q} 4=358 ; \operatorname{Exp}=615.5$ ). Players born in the first 3 months of the year were overrepresented compared with those born in the other quarters $(p<$ 0.001; OR Q1:Q4 = 3.69; OR S1:S2 = 4.38). Moreover, players born in the last 3 months of the year were less frequent than athletes born in all the other quarters $(p<0.001)$.

\section{Relative age effect vs. age categories}

When athletes were analysed by age categories (Table 1), the chi-square analysis indicated uneven birthdate distributions in both U-20 $(p<0.001 ; \omega=0.42)$ and senior $(p<0.001 ; \omega=0.21)$ age categories. In the U-20 category, athletes born in the first 3 months of the year were overrepresented in comparison with those born in the last 3 months of the year $(p<0.002)$. In addition, players born in the last 3 months of the year were less frequent than those born in the other quarters of the year $(p<0.002)$. In the senior category, athletes born in Q1 $(p<0.001), \mathrm{Q} 2(p<0.001)$, and Q3 $(p<0.007)$ were overrepresented in comparison with those born in the last 3 months of the year.

\section{Relative age effect vs. competitive level}

When athletes were analysed by age category and competitive level (Table 2), the chi-square analysis indicated that players born in the first semester of the year were overrepresented in both age categories and competitive levels $(p<0.001)$. However, the magnitude

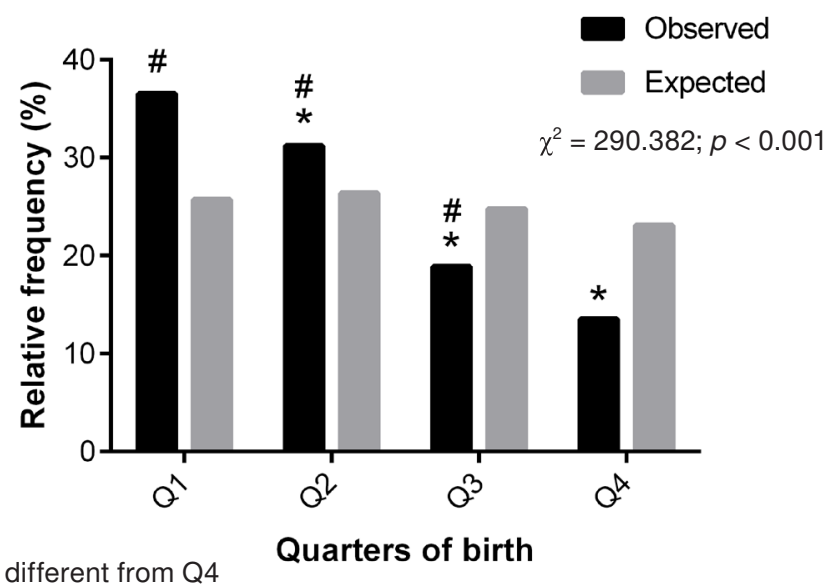

* different from Q1

Figure 1. Relative observed and expected birthdate frequencies of elite soccer athletes

of this overrepresentation was larger in the U-20 category, in both competitive level A and level B $(\omega=0.46$, $\omega=0.36$, respectively), than in senior players $(\omega=$ 0.196, $\omega=0.23$, respectively). Overall, athletes born in Q1 and Q2 were more frequent than those born in Q4 $(p<0.001)$, regardless of the age category or competitive level. However, it was only in the U-20 category that players born in Q4 were less frequent than those born in all the other quarters of the year $(p<$ 0.005).

\section{Relative age effect vs. playing position}

When players were analysed by their age category and playing position (Table 3), the chi-square analysis indicated that athletes born in the first semester were more frequent in all playing positions in both U-20 $(p<0.001)$ and senior $(p<0.001)$ categories, except for the goalkeepers in the latter $(p=0.89)$. For all the other playing positions, athletes born in the first semester were more frequent than those born in the last 3 months of the year $(p<0.003)$. The magnitude of the effect was larger in U-20 forwards $(\omega=$

Table 1. Brazilian senior and U-20 soccer players' birthdates distribution by age category

\begin{tabular}{|c|c|c|c|c|c|c|c|c|c|}
\hline \multirow{2}{*}{ Category } & Q1 & Q2 & Q3 & $\mathrm{Q} 4$ & \multirow{2}{*}{$\chi^{2}$} & \multirow{2}{*}{$p$} & \multirow{2}{*}{$\omega$} & OR Q1:Q4 & $O R 1^{\text {st }}: 2^{\text {nd }}$ \\
\hline & (Exp) & (Exp) & (Exp) & (Exp) & & & & $95 \% \mathrm{CI}$ & $95 \%$ CI \\
\hline Senior & $\begin{array}{c}390^{\mathrm{cd} d} \\
(305.5)\end{array}$ & $\begin{array}{c}353^{\mathrm{c}, \mathrm{d}} \\
(313.9)\end{array}$ & $\begin{array}{c}243^{\mathrm{d}} \\
(295.4)\end{array}$ & $\begin{array}{c}203 \\
(274.3)\end{array}$ & 56.745 & $<0.001$ & 0.218 & $\begin{array}{c}2.37 \\
1.95-2.88\end{array}$ & $\begin{array}{c}1.96 \\
1.67-2.31\end{array}$ \\
\hline Under-20 & $\begin{array}{l}580^{b, c, d} \\
(377.5)\end{array}$ & $\begin{array}{c}477^{\mathrm{c,d}} \\
(387.9)\end{array}$ & $\begin{array}{c}259^{d} \\
(365.2)\end{array}$ & $\begin{array}{c}155 \\
(340.4)\end{array}$ & 261.025 & $<0.001$ & 0.421 & $\begin{array}{c}5.53 \\
4.54-6.73\end{array}$ & $\begin{array}{c}6.52 \\
5.55-7.66\end{array}$ \\
\hline
\end{tabular}

$\mathrm{Q}$ - birth quarter, (Exp) - expected distribution, $\omega$ - effect size, OR Q1:Q4 - odds ratio from Q1 to Q4, OR $1^{\text {st }}: 2^{\text {nd }}-$ odds ratio from $1^{\text {st }}$ semester to $2^{\text {nd }}$ semester, ${ }^{\text {b }}$ different from Q2, ${ }^{\mathrm{c}}$ different from Q3, ${ }^{\mathrm{d}}$ different from Q4 


\section{HUMAN MOVEMENT}

L.S. Figueiredo et al., Relative age effect in Brazilian soccer

Table 2. Brazilian senior and U-20 soccer players' birthdates distribution by series played

\begin{tabular}{|c|c|c|c|c|c|c|c|c|c|c|}
\hline \multirow{2}{*}{ Series } & \multirow{2}{*}{ Category } & Q1 & Q2 & Q3 & Q4 & \multirow{2}{*}{$\chi^{2}$} & \multirow{2}{*}{$p$} & \multirow{2}{*}{$\omega$} & OR Q1:Q4 & $O R 1^{\text {st }}: 2^{\text {nd }}$ \\
\hline & & $(\mathrm{Exp})$ & $(\mathrm{Exp})$ & $(\mathrm{Exp})$ & $(\mathrm{Exp})$ & & & & $95 \% \mathrm{CI}$ & $95 \%$ CI \\
\hline \multirow{2}{*}{$\mathrm{A}$} & Senior & $\begin{array}{c}180^{\mathrm{c}, \mathrm{d}} \\
(145.2)\end{array}$ & $\begin{array}{c}168^{\mathrm{c}, \mathrm{d}} \\
(149.3)\end{array}$ & $\begin{array}{c}119 \\
(140.5)\end{array}$ & $\begin{array}{c}99 \\
(131)\end{array}$ & 21.781 & $<0.001$ & 0.196 & $\begin{array}{c}2.199 \\
1.66-2.91\end{array}$ & $\begin{array}{c}2.548 \\
2-3.24\end{array}$ \\
\hline & Under-20 & $\begin{array}{l}342^{\mathrm{b}, \mathrm{c}, \mathrm{d}} \\
(213.7)\end{array}$ & $\begin{array}{c}272^{\mathrm{c}, \mathrm{d}} \\
(219.7)\end{array}$ & $\begin{array}{c}140^{\mathrm{d}} \\
(206.8)\end{array}$ & $\begin{array}{c}79 \\
(192.8)\end{array}$ & 178.154 & $<0.001$ & 0.462 & $\begin{array}{c}6.648 \\
5.08-8.70 \\
\end{array}$ & $\begin{array}{c}7.86 \\
6.32-9.78 \\
\end{array}$ \\
\hline \multirow{2}{*}{ B } & Senior & $\begin{array}{c}210^{\mathrm{c}, \mathrm{d}} \\
(159.9)\end{array}$ & $\begin{array}{c}185^{\mathrm{c}, \mathrm{d}} \\
(164.3)\end{array}$ & $\begin{array}{c}124 \\
(154.7)\end{array}$ & $\begin{array}{c}104 \\
(144.2)\end{array}$ & 35.615 & $<0.001$ & 0.239 & $\begin{array}{c}2.537 \\
1.94-3.32\end{array}$ & $\begin{array}{c}3.001 \\
2.38-3.78\end{array}$ \\
\hline & Under-20 & $\begin{array}{c}238^{\mathrm{c}, \mathrm{d}} \\
(163.7)\end{array}$ & $\begin{array}{c}205^{\mathrm{c}, \mathrm{d}} \\
(168.2)\end{array}$ & $\begin{array}{c}119^{\mathrm{d}} \\
(158.4)\end{array}$ & $\begin{array}{c}76 \\
(147.6)\end{array}$ & 86.307 & $<0.001$ & 0.367 & $\begin{array}{c}4.399 \\
3.3-5.87\end{array}$ & $\begin{array}{c}5.048 \\
3.98-6.40\end{array}$ \\
\hline
\end{tabular}

Q - birth quarter, (Exp) - expected distribution, $\omega$ - effect size, OR Q1:Q4 - odds ratio from Q1 to Q4, OR $1^{\text {st }}: 2^{\text {nd }}-$ odds $^{\text {. }}$ ratio from $1^{\text {st }}$ semester to $2^{\text {nd }}$ semester, ${ }^{\text {b }}$ different from Q2, ${ }^{\mathrm{c}}$ different from Q3, ${ }^{\mathrm{d}}$ different from Q4

Table 3. Brazilian senior and U-20 soccer players' birthdates distribution by playing position

\begin{tabular}{|c|c|c|c|c|c|c|c|c|c|c|}
\hline \multirow{2}{*}{ Category } & \multirow{2}{*}{ Position } & Q1 & Q2 & Q3 & Q4 & \multirow{2}{*}{$\chi^{2}$} & \multirow{2}{*}{$p$} & \multirow{2}{*}{$\omega$} & OR Q1:Q4 & $O R 1^{\text {st }}: 2^{\text {nd }}$ \\
\hline & & $(\operatorname{Exp})$ & (Exp) & (Exp) & $(\operatorname{Exp})$ & & & & $95 \% \mathrm{CI}$ & $95 \% \mathrm{CI}$ \\
\hline \multirow{4}{*}{ Senior } & ATK & $\begin{array}{c}91^{\mathrm{c}, \mathrm{d}} \\
(72.1)\end{array}$ & $\begin{array}{c}88^{\mathrm{d}} \\
(74.1)\end{array}$ & $\begin{array}{c}56 \\
(69.8)\end{array}$ & $\begin{array}{c}46 \\
(65)\end{array}$ & 15.843 & 0.001 & 0.237 & $\begin{array}{c}2.45 \\
1.64-3.66\end{array}$ & $\begin{array}{c}3.08 \\
2.18-4.343\end{array}$ \\
\hline & MDL & $\begin{array}{c}136^{\mathrm{c}, \mathrm{d}} \\
(101.9)\end{array}$ & $\begin{array}{c}120^{\mathrm{c}, \mathrm{d}} \\
(104.7)\end{array}$ & $\begin{array}{c}76 \\
(98.6)\end{array}$ & $\begin{array}{c}65 \\
(91.9)\end{array}$ & 26.701 & $<0.001$ & 0.259 & $\begin{array}{c}2.66 \\
1.90-3.73\end{array}$ & $\begin{array}{c}3.3 \\
2.46-4.41\end{array}$ \\
\hline & DEF & $\begin{array}{l}128^{\mathrm{d}} \\
(97.5)\end{array}$ & $\begin{array}{c}108^{\mathrm{d}} \\
(100.2)\end{array}$ & $\begin{array}{c}80 \\
(94.4)\end{array}$ & $\begin{array}{c}64 \\
(87.9)\end{array}$ & 18.839 & $<0.001$ & 0.223 & $\begin{array}{c}2.51 \\
1.78-3.53\end{array}$ & $\begin{array}{c}2.69 \\
2.04-3.60\end{array}$ \\
\hline & GLK & $\begin{array}{c}35 \\
(33.6)\end{array}$ & $\begin{array}{c}37 \\
(34.5)\end{array}$ & $\begin{array}{c}32 \\
(32.5)\end{array}$ & $\begin{array}{c}27 \\
(30.3)\end{array}$ & 0.602 & 0.896 & 0.067 & $\begin{array}{c}1.4 \\
0.79-2.49\end{array}$ & $\begin{array}{c}1.49 \\
0.92-2.42\end{array}$ \\
\hline \multirow{4}{*}{ U-20 } & ATK & $\begin{array}{l}151^{\mathrm{c}, \mathrm{d}} \\
(93.9)\end{array}$ & $\begin{array}{l}116^{\mathrm{c}, \mathrm{d}} \\
(96.5)\end{array}$ & $\begin{array}{c}64^{\mathrm{d}} \\
(90.9)\end{array}$ & $\begin{array}{c}35 \\
(84.7)\end{array}$ & 75.737 & $<0.001$ & 0.455 & $\begin{array}{c}6.86 \\
4.56-10.31\end{array}$ & $\begin{array}{c}7.27 \\
5.25-10.08\end{array}$ \\
\hline & MDL & $\begin{array}{c}186^{\mathrm{c}, \mathrm{d}} \\
(117.3) \\
\end{array}$ & $\begin{array}{c}186^{\mathrm{c}, \mathrm{d}} \\
(120.5) \\
\end{array}$ & $\begin{array}{c}78 \\
(113.5) \\
\end{array}$ & $\begin{array}{c}55 \\
(105.7) \\
\end{array}$ & 96.177 & $<0.001$ & 0.436 & $\begin{array}{c}4.77 \\
3.42-6.65 \\
\end{array}$ & $\begin{array}{c}7.82 \\
5.91-10.35 \\
\end{array}$ \\
\hline & $\mathrm{DEF}$ & $\begin{array}{l}186^{\mathrm{b}, \mathrm{c}, \mathrm{d}} \\
(129.6)\end{array}$ & $\begin{array}{c}131^{\mathrm{c}, \mathrm{d}} \\
(133.2)\end{array}$ & $\begin{array}{c}89^{\mathrm{d}} \\
(125.4) \\
\end{array}$ & $\begin{array}{c}51 \\
(116.9) \\
\end{array}$ & 74.824 & $<0.001$ & 0.405 & $\begin{array}{c}5.46 \\
3.87-7.71 \\
\end{array}$ & $\begin{array}{c}5.13 \\
3.87-6.79 \\
\end{array}$ \\
\hline & GLK & $\begin{array}{c}57^{\mathrm{c}, \mathrm{d}} \\
(36.7)\end{array}$ & $\begin{array}{c}44^{\mathrm{d}} \\
(37.7)\end{array}$ & $\begin{array}{c}28 \\
(35.5)\end{array}$ & $\begin{array}{c}14 \\
(33.1)\end{array}$ & 24.887 & $<0.001$ & 0.417 & $\begin{array}{c}6.11 \\
3.22-11.56\end{array}$ & $\begin{array}{c}5.78 \\
3.48-9.62\end{array}$ \\
\hline
\end{tabular}

Q - birth quarter, (Exp) - expected distribution, $\omega$ - effect size, OR Q1:Q4 - odds ratio from Q1 to Q4, OR $1^{\text {st }}: 2^{\text {nd }}-$ odds $^{2}$ ratio from $1^{\text {st }}$ semester to $2^{\text {nd }}$ semester, ATK - attacker, MDL - midfielder, DEF - defender, GLK - goalkeeper

${ }^{\mathrm{b}}$ different from Q2, ${ }^{\mathrm{c}}$ different from Q3, ${ }^{\mathrm{d}}$ different from Q4

$0.45)$, midfielders $(\omega=0.43)$, defenders $(\omega=0.40)$, and goalkeepers $(\omega=0.41)$ when compared with senior forwards $(\omega=0.23)$, midfielders $(\omega=0.25)$, defenders $(\omega=0.22)$, and goalkeepers $(\omega=0.06)$.

\section{Discussion}

In the present study, we investigated the presence of RAE in Brazilian elite soccer athletes from U-20 and senior categories and analysed whether playing position and competitive level were associated with RAE. As predicted, our main findings confirmed the existence of RAE among athletes in both age categories (more pronounced in the U-20 category), both competitive levels (Series A or B), and all playing positions, except for goalkeepers in the senior category. These observations corroborate those from previous studies with elite soccer athletes both in Brazil [11, 
21] and worldwide [5, 18]. Moreover, this study indicated different RAE magnitudes in U-20 and Senior Brazilian National Soccer League athletes, depending on playing position and competitive level. Since RAE occurs in Brazilian elite soccer athletes, coaches and stakeholders are warranted to implement counter-RAE interventions, aiming to reduce the loss of potential sporting talents because of inequalities resulting from the age grouping system.

In our study, RAE of different magnitudes was found in U-20 and senior categories $(\omega=0.42, \omega=0.21$, respectively). Even though RAE decreased as age categories increased in our study, it was still present in both age categories, which indicates that athletes' birthdates continue to play an important role in the selection of elite players, even in the senior category [3]. This seems to be associated with the pressure for immediate results imposed on coaches of Brazilian youth categories [24]. Indeed, previous studies have consistently shown that Brazilian youth coaches are more likely to select relatively older players, as they may achieve higher performance in the short term [10, 25]. Nevertheless, the reduction in the magnitude of the effect suggests that selecting supposedly more physically developed athletes in younger categories because they are relatively older does not represent great advantages for the insertion of players in the senior level. In fact, the reduction of RAE magnitude as the categories advance indicates that a significant proportion of young athletes born closer to the cut-off dates are not reaching the senior category. This idea has already been reported in the Brazilian soccer context, along with the notion that relatively younger athletes may actually benefit in the long run from competing with relatively older peers [24].

The reduction in the magnitude of the RAE with the increase in age category may be a result of the interaction between several factors (e.g. technical, tactical, and psychological aspects) that are warranted to influence elite athletes' selection and adherence in older age categories [3, 15]. It has been proposed that relatively younger athletes may benefit from competing with relatively older peers [5]. Since relatively older athletes are more likely to be bigger, faster, and stronger, relatively younger athletes need to develop other resources to thrive in this disadvantaged environment. The constant competition with older peers, however, may result in the development of more skilled players, which in the long-term could provide younger players with a greater chance of success if they ever manage to reach the senior category [5]. In line with these propositions, Ramos-Filho and Ferreira [24] identified a re- verse RAE concerning sports performance in professional Brazilian soccer players. Similarly, Ashworth and Heyndels [26] demonstrated that relatively younger German soccer players tended to earn higher wages when they reached the professional league. Taken together, these results suggest that coaches must account for factors other than age-related differences in the early selection of elite athletes.

The analysis of players by the competitive level showed that RAE was present in both divisions, regardless of the age category. The analysis of the odds ratios, however, indicated a contrary trend for the magnitude of the effect in the U-20 and senior categories. In the U-20 category, players born in the first semester were 7.86 times more likely to be part of Series A squads than those born in the second semester $(O R=$ 5.05 in Series B). On the other hand, in the senior category, players born in the first semester were 2.55 times more likely to be part of Series A squads than those born in the second semester $(O R=3.0$ in Series B). These results indicate that the composition of Series A in the U-20 squads seems to have greater remnants of decisions made by coaches in lower categories, based on possible advantages in the development stages. Conversely, in the senior category, the opposite occurs, since fewer relatively younger players compose Series A squads compared with Series B squads. Since the most skilled athletes (not necessarily those who are bigger and stronger) are expected in a greater proportion in the Series A teams, these results indicate that over time, there seems to be a natural re-evaluation of players [5]. This correction, via the athletes' transfer market, seems to reposition the younger athletes to more qualified teams in the senior category.

The playing position analyses indicated an overrepresentation of relatively older players in all the line playing positions (i.e. forwards, midfielders, and defenders), in both age categories. Once again, higher magnitude effects were found in the U-20 category (medium-sized effects) rather than in the senior category (small-sized effects). These analyses also imply that effects were similar among positions in the U-20 and all line positions in the senior category. Our results are different from those obtained by Salinero et al. [27], who only found RAE in some of the playing positions, which varied depending on the different European leagues investigated. Overall, evidence reinforces the notion that RAE is multifactorial [8] and that the results found in playing position analysis are contextdependent. We assume that the prevalence of RAE in most playing positions in our study is a consequence of the high competition for spots as line players in Bra- 
zilian soccer because of the high popularity of this sport. The prevalence of RAE in all line positions also follows the current soccer physical demands. Since elite soccer increasingly demands high game intensities [28], faster and stronger athletes tend to be preferred in all line positions. This could explain why youth coaches continuously favour relatively older athletes since they are more likely to show increased physical performance earlier, owing to maturation [17].

An exception was the case of goalkeepers since RAE was not found in this position in any age category investigated in this study. This finding is in line with the observations by de Souza et al. [29], who also did not report RAE for elite senior Brazilian goalkeepers. One of the explanations provided by these authors to these results is based on the greater prestige and financial gains provided by line positions, which would make young athletes more prone to compete for spots in these positions rather than for goalkeeper spots in younger categories. Our results provide some advances in this discussion since RAE on the goalkeeper position was only verified in the U-20 category, but not in the senior category. The absence of RAE in elite Brazilian goalkeepers seems to be specific to the senior category, and not to result from low competitiveness in the grassroots categories. The lack of RAE elimination in goalkeepers from the senior category is likely due to the specificity of the skills, training, and selection in this position [30]. The presence of goalkeepers' coaches and trainers in the selection processes and throughout the development of sports talents may minimize the focus on maturational aspects and promote the emphasis on the position-specific skills, aiming at longterm development [29]. Furthermore, the goalkeepers' careers tend to be longer, with their peak performance reaching later than in line players [30]. These facts demonstrate that in this position, the players need more time to develop specific skills, which allows the valuation of aspects other than maturation in the selection processes. To confirm these hypotheses, future longitudinal studies are warranted to further understand the role of RAE among goalkeepers.

One of the limitations of the present study was that data were collected in a single moment in time, comprising male athletes who were part of squads participating in the 2019 Brazilian soccer championships. This precluded an overview of the phenomenon in elite soccer athletes, allowing the rather specific context of RAE in the Brazilian soccer league only. Also, we did not control the effective participation times of athletes in the competitions, only their registration in $\mathrm{CBF}$ to participate in a squad. This information could pro- vide important insights into the effects of RAE not only on selection but also on the athletic development opportunities received by athletes depending on their birthdates [31]. Future investigations are warranted to overcome these limitations by using longitudinal approaches and by controlling the participation of athletes in official matches.

\section{Conclusions}

In summary, RAE is present in U-20 and senior age categories in elite Brazilian soccer athletes, in both competitive levels and all playing positions, except for goalkeepers in the senior category. This indicates that relatively older athletes are systematically favoured in the Brazilian youth soccer system, owing to developmental advantages that might cause better performance in the short term [25]. These results have important practical implications for the development of talents in Brazilian soccer, especially regarding the athlete selection processes. Since research has consistently shown that this selection bias in the early stage of athletes' development is not associated with long-term sports achievements [32], counter-RAE policies are necessary to minimize the loss of potential sports talents. Some interventions in this direction have been proposed, such as educating coaches about RAE incidence in soccer systems [1]; using numbered shirts depending on birthdates during tests to highlight chronological differences between players [33]; and changing the regulations in youth soccer competitions, including the mandatory registration of a minimum number of athletes born in the second semester [5].

A paradigm shift in youth categories is necessary to reduce the extensive RAE in the Brazilian soccer context, as coaches and stakeholders should place less investment in the short-term pursuit for sporting achievements in these categories. As long as coaches feel the pressure to win competitions in the grassroots categories, they are likely to favour relatively older young athletes, as they tend to be bigger and stronger [6]. In this sense, technical, tactical, and psychological aspects that are so important in elite-level sport become secondary factors when it comes to selection and playing opportunities. Unless long-term talent development policies are implemented in Brazilian soccer, the inequalities generated by RAE will tend to be maintained in this sports system, even reaching the senior category. 


\section{Disclosure statement}

No author has any financial interest or received any financial benefit from this research.

\section{Conflict of interest}

The authors state no conflict of interest.

\section{References}

1. Musch J, Grondin S. Unequal competition as an impediment to personal development: a review of the relative age effect in sport. Dev Rev. 2001;21(2):147-167; doi: 10.1006/drev.2000.0516.

2. Malina RM, Rogol AD, Cumming SP, Coelho e Silva MJ, Figueiredo AJ. Biological maturation of youth athletes: assessment and implications. Br J Sports Med. 2015; 49(13):852-859; doi: 10.1136/bjsports-2015-094623.

3. Cobley S, Baker J, Wattie N, McKenna J. Annual agegrouping and athlete development: a meta-analytical review of relative age effects in sport. Sports Med. 2009; 39(3):235-256; doi: 10.2165/00007256-20093903000005.

4. Helsen WF, Starkes JL, Winckel JV. The influence of relative age on success and dropout in male soccer players. Am J Hum Biol. 1998;10(6):791-798; doi: 10.1002/ (SICI)1520-6300(1998)10:6<791::AID-AJHB10>3.0. $\mathrm{CO} ; 2-1$.

5. Rađa A, Padulo J, Jelaska I, Ardigò LP, Fumarco L. Relative age effect and second-tiers: no second chance for later-born players. PLoS One. 2018;13(8):e0201795; doi: 10.1371/journal.pone.0201795.

6. Morales Júnior VR, Garcia Alves IV, Galatti LR, Rodrigues Marques RF. The relative age effect on Brazilian elite futsal: men and women scenarios. Motriz Rev Educ Fis. 2017;23(3):e101704; doi: 10.1590/s1980-657420 1700030016.

7. Figueiredo LS, Gantois P, de Lima-Junior D, se Sousa Fortes L, de Souza Fonseca F. The relationship between relative age effects and sex, age categories and playing positions in Brazilian National Handball Teams. Motriz Rev Educ Fis. 2020;26(4):e10200045; doi: 10.1590/ S1980-6574202000040045.

8. Wattie N, Schorer J, Baker J. The relative age effect in sport: a developmental systems model. Sports Med. 2015;45(1):83-94; doi: 10.1007/s40279-014-0248-9.

9. Villar R, Zühl CA. Effect of chronological age and biological maturation on physical fitness in soccer players aged 13 to 17 years [in Portuguese]. Motricidade. 2006; 2(2):69-79.

10. Massa M, Costa EC, Moreira A, Thiengo CR, de Lima MR, Marquez WQ, et al. The relative age effect in soccer: a case study of the São Paulo Football Club. Rev Bras Cineantropom Desempenho Hum. 2014;16(4):399-405; doi: 10.5007/1980-0037.2014v16n4p399.

11. Altimari JM, Bortolotti H, dos Santos-Junior N, Altimari LR, de Moraes AC. Birth month distribution and anthropometric measures of U-15 national elite soccer players. Rev Bras Cineantropom Desempenho Hum. 2018;20(2):211-218; doi: 10.5007/1980-0037.2018v2 0n2p211.

12. Reilly T. The science of training - soccer: a scientific approach to developing strength, speed and endurance. Abingdon: Routledge; 2007.

13. Turner AN, Stewart PF. Strength and conditioning for soccer players. Strength Cond J. 2014;36(4):1-13; doi: 10.1519/SSC.0000000000000054.

14. Campos FAD, Campos LCB, Pellegrinotti IL, Gómez MA. The relative age effect in soccer: an analysis of the U20 Libertadores Cup. Int J Exerc Sci. 2017;10(8):1157-1164.

15. Fonseca FS, Figueiredo LS, Gantois P, de Lima-Junior D, Fortes LS. Relative age effect is modulated by playing position but is not related to competitive success in elite under-19 handball athletes. Sports. 2019;7(4):91; doi: $10.3390 /$ sports7040091.

16. Romann M, Fuchslocher J. Relative age effects in Swiss junior soccer and their relationship with playing position. Eur J Sport Sci. 2013;13(4):356-363; doi: 10.1080/ 17461391.2011.635699.

17. Sierra-Díaz MJ, González-Víllora S, Pastor-Vicedo JC, Serra-Olivares J. Soccer and relative age affect: a walk among elite players and young players. Sports. 2017; 5(1):5; doi: 10.3390/sports5010005.

18. Götze M, Hoppe MW. Relative age effect in elite German soccer: influence of gender and competition level. Front Psychol. 2021;11:587023; doi: 10.3389/fpsyg. 2020.587023.

19. Teoldo I, Cardoso F. Talent map: how demographic rate, human development index and birthdate can be decisive for the identification and development of soccer players in Brazil. Sci Med Football. Published online: 22 Feb 2021; doi: 10.1080/24733938.2020.1868559.

20. Costa VT, Simim MA, Noce F, Costa IT, Samulski DM, Moraes LC. Comparison of relative age of elite athletes participating in the 2008 Brazilian soccer championship series A and B. Motricidade. 2009;5(3):13-17; doi: 10.6063/motricidade.5(3).190.

21. Teoldo Da Costa I, Albuquerque RM, Garganta J. Relative age effect in Brazilian soccer players: a historical analysis. Int J Perform Anal Sport. 2012;12(3):563-570; doi: 10.1080/24748668.2012.11868619.

22. Delorme N, Boiché J, Raspaud M. Relative age effect in elite sports: methodological bias or real discrimination? Eur J Sport Sci. 2010;10(2):91-96; doi: 10.1080/174613 90903271584.

23. Bronson FH. Seasonal variation in human reproduction: environmental factors. Q Rev Biol. 1995;70(2): 141-164; doi: 10.1086/418980.

24. Ramos-Filho L, Ferreira MP. The reverse relative age effect in professional soccer: an analysis of the Brazilian National League of 2015. Eur Sport Manag Q. 2021; 21(1):78-93; doi: 10.1080/16184742.2020.1725089.

25. Teixeira AS, da Silva JF, dos Santos PC, do Nascimento Salvador PC, de Souza Campos F, de Lucas RD, et al. Relative age effect, skeletal maturation and aerobic run- 


\section{HUMAN MOVEMENT}

L.S. Figueiredo et al., Relative age effect in Brazilian soccer

ning performance in youth soccer players. Motriz Rev Educ Fis. 2018;24(4):e101864; doi: 10.1590/s19806574201800040018.

26. Ashworth J, Heyndels B. Selection bias and peer effects in team sports: the effect of age grouping on earnings of German soccer players. J Sports Econ. 2007;8(4):355377; doi: 10.1177/1527002506287695.

27. Salinero JJ, Pérez González B, Burillo P, Lesma ML. Relative age effect in European professional football. Analysis by position. J Hum Sport Exerc. 2013;8(4): 966-973; doi: 10.4100/jhse.2013.84.07.

28. Wallace JL, Norton KI. Evolution of World Cup soccer final games 1966-2010: game structure, speed and play patterns. J Sci Med Sport. 2014;17(2):223-228; doi: 10.1016/j.jsams.2013.03.016.

29. De Souza IS, Vicentini L, dos Reis Morbi M, Rodrigues Marques RF. The relative age effect on soccer goalkeeper training in Brazil: scenarios of the male and female elites. J Phys Educ. 2020;31(1):e-3173; doi: 10.4025/ jphyseduc.v31i1.3173.

30. Da Cunha Voser R, Vieira Guimarães MG, Rodrigues Ribeiro E. Football: history, technique and goalkeeper training [in Portuguese]. Porto Alegre: EDIPUCRS; 2006.

31. Krahenbühl T, Leonardo L. The relative age effect: coaches' choices as evidence of social influence on youth handball. J Phys Educ Sport. 2020;20(5):2460-2467; doi: 10.7752/jpes.2020.05337.

32. Hancock DJ, Adler AL, Côté J. A proposed theoretical model to explain relative age effects in sport. Eur J Sport Sci.2013;13(6):630-637;doi:10.1080/17461391.2013. 775352.

33. Mann DL, van Ginneken PJMA. Age-ordered shirt numbering reduces the selection bias associated with the relative age effect. J Sports Sci. 2017;35(8):784-790; doi: 10.1080/02640414.2016.1189588. 